\title{
Pathways of Biological Production in Large Rivers
}

\section{Large Rivers are among the Most Productive and Diverse Aquatic Ecosystems}

Large rivers are among the most biologically productive and diverse of aquatic ecosystems and also provide important economic, recreational, and aesthetic values. Biological production is the amount of plants and animals produced, and diversity is the number of species present. Biological production and diversity provide value to society through fishing, bird-watching, and waterfowl hunting. Aquatic plants take up excess nutrients-such as nitrate and phosphorus-from agricultural and urban runoff, and some of those plants are the food base for waterfowl and fish. The walleye caught by an angler or the duck bagged by a hunter is the end result of a complex series of processes that provide the energy needed for these animals to grow and survive. To conserve these valued resources, it is important to

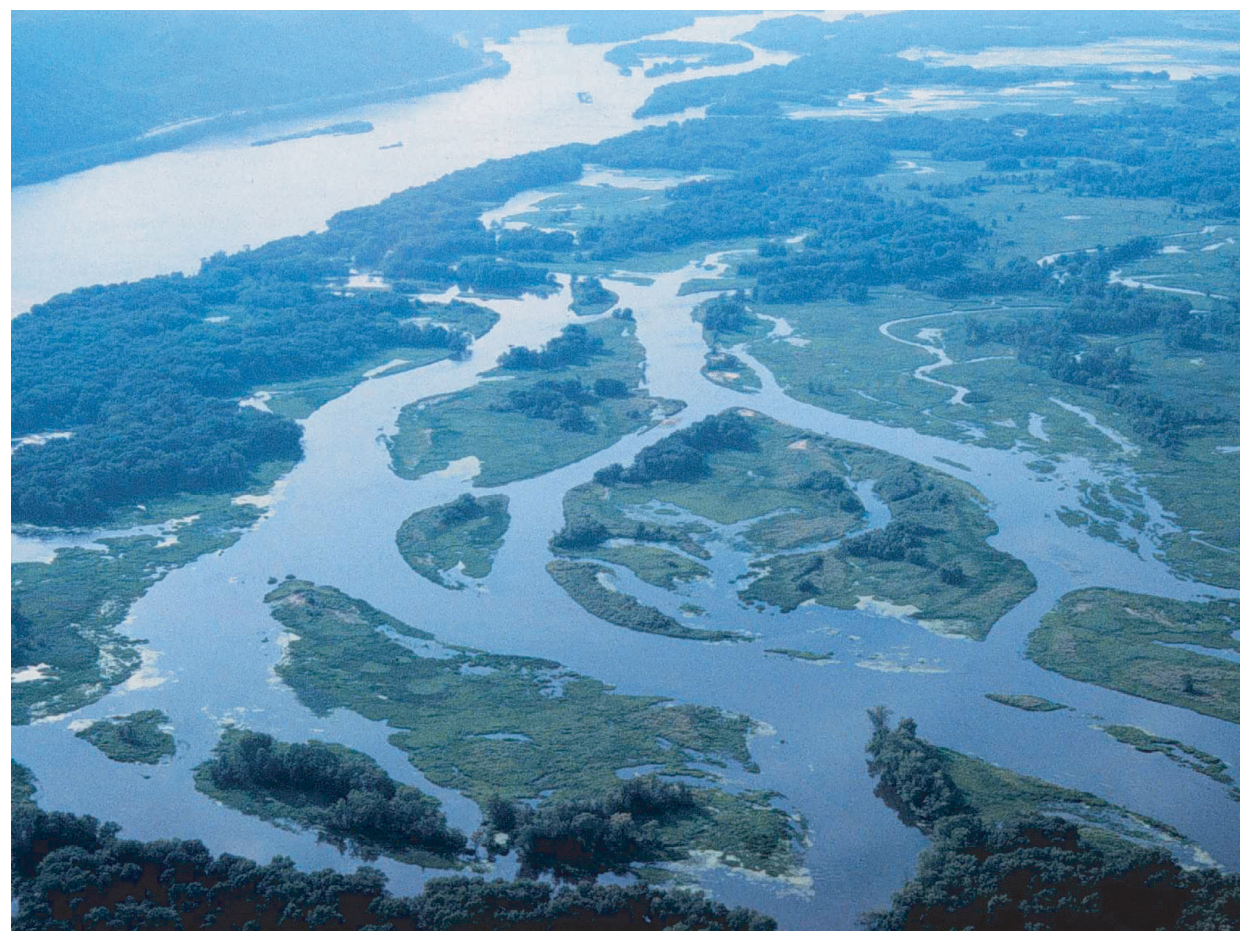

The floodplains of large rivers provide a complex mix of aquatic and terrestrial habitats that support high biological diversity and production of plants, fish, birds, and mammals. We are presently studying factors that affect fish production in both the deep channels and in backwaters, or off-channel, areas.

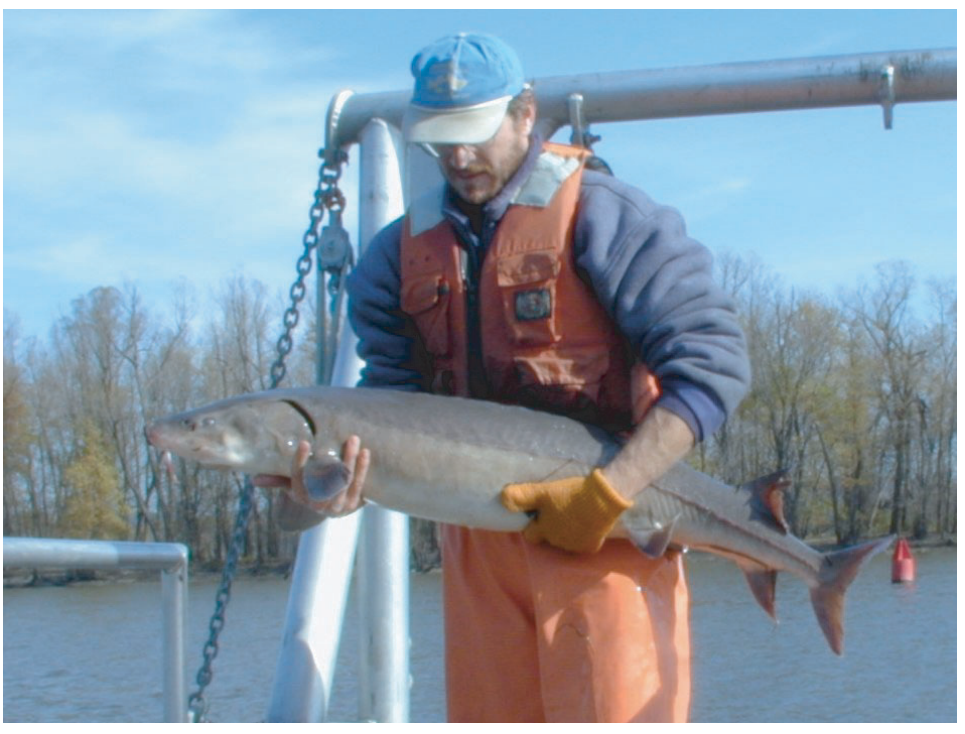

Large rivers support production of valuable fishes, including the lake sturgeon, above. We are presently studying what habitats support fishes in the deep channels of large rivers and factors that may be affecting their abundance. understand the energy sources and pathways, or food webs, that result in high biological production and diversity in large rivers.

\section{Many Theories but too Little Knowledge}

Scientists don't know the specific factors that support the high biological production and diversity of large rivers. We do know, however, that carbon and nutrients are the basic building blocks of biological production. Competing theories suggest that the main sources of carbon and nutrients constituting the fish in large rivers originate in the floodplains, or perhaps the upstream tributaries, or even the plants that grow within the river itself. Other theories suggest that floodplain complexity - the many physical processes such as changing flows and the mosaic of water and land habitats-is key to biological productivity.

Many human activities on large rivers also affect biological production. For example, many large rivers support commercial navigation. Navigation traffic may directly affect plants and

点 


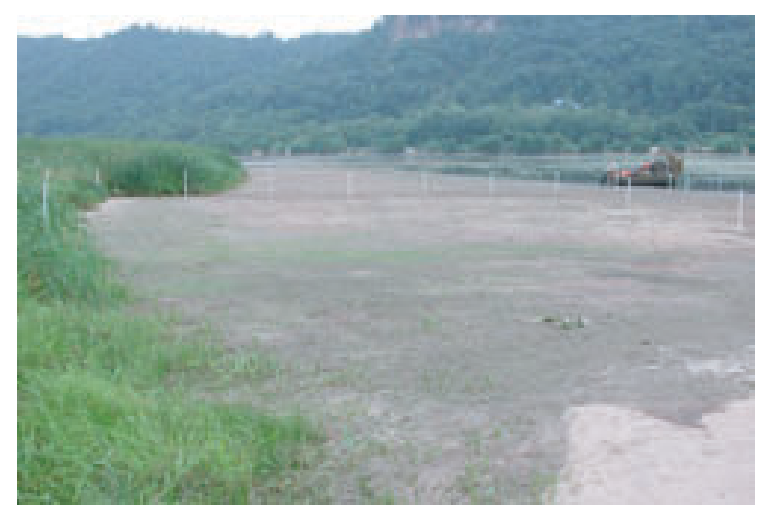

We are studying the effects of experimental midsummer water-level drawdowns on floodplain vegetation on the Mississippi River near Onalaska, Wisconsin. When river water is lowered and mudflats are exposed, plants valuable to wildlife are able to germinate. The upper photograph shows a study site soon after drawdown, and the lower photo shows vegetation production 22 days later.

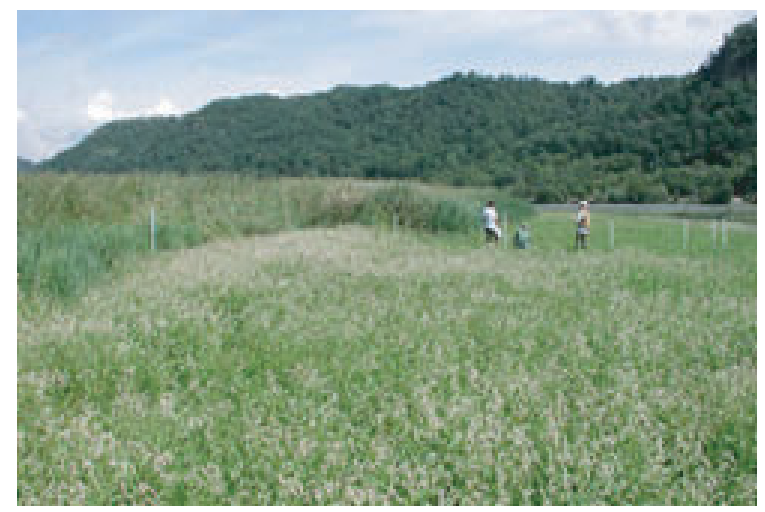

animals that live in or near the navigation channels. The structures that support navigation, such as dams and wing dikes, may indirectly affect plants and animals by changing water levels and flow patterns. In addition, production and biological diversity are affected by commercial and recreational harvest as well as predation and competition among species. Non-native species that have been introduced into American rivers can also affect production and diversity. A combination of these factors is likely at work in large rivers, but few of these theories or concepts have been critically evaluated. Thus, we are unable to predict how the plants and animals of large rivers will respond to future conditions or to management alternatives.

\section{Painting the Big Picture}

Scientists at the Upper Midwest Environmental Sciences Center seek to discover the major productivity pathwaysthe mechanisms that support biological production - of the large river ecosystems of the United States. With this knowledge, we may develop innovative and efficient ways to conserve those ecosystems while continuing to provide important economic benefits. To accomplish this task, we are using existing data and field studies to identify critical productivity pathways, starting with the Upper Mississippi River system. Despite information from previous studies, significant gaps exists in our data: identification of the major energy pathways and food webs and the roles of river management, water-level fluctuations, habitat connections, nutrient processing, and floodplain complexity in the production of fishes and other aquatic life. This additional knowledge will provide the basis for predictive models of biological production in large rivers. These models will be useful for developing and testing innovative strategies to better manage large rivers.

\section{Current and Future Studies}

We are presently studying how midsummer water-level drawdowns on the Upper Mississippi River affect the production of aquatic plants. In a drawdown, managers use the river's locks and dams to manipulate water levels to partly mimic the natural fluctuations that prevailed before the locks and dams were constructed. We are also studying the importance of off-channel areas and deep channels to fish production and the effects of dams and navigation traffic on the movements, mortality, and distribution of fishes. Each of these studies addresses either direct or indirect effects of river management on important aspects of biological production. Our current studies are not the end of the story. Future work will focus on the roles of carbon and nutrient processing and how that processing is affected by river management alternatives.

\section{For more information, contact}

\author{
Steve Gutreuter \\ USGS Upper Midwest Environmental Sciences Center \\ 2630 Fanta Reed Road \\ La Crosse, WI 54603
}

Phone: 608.783.6222

Email: sgutreuter@usgs.gov

\section{http://www.umesc.usgs.gov/}

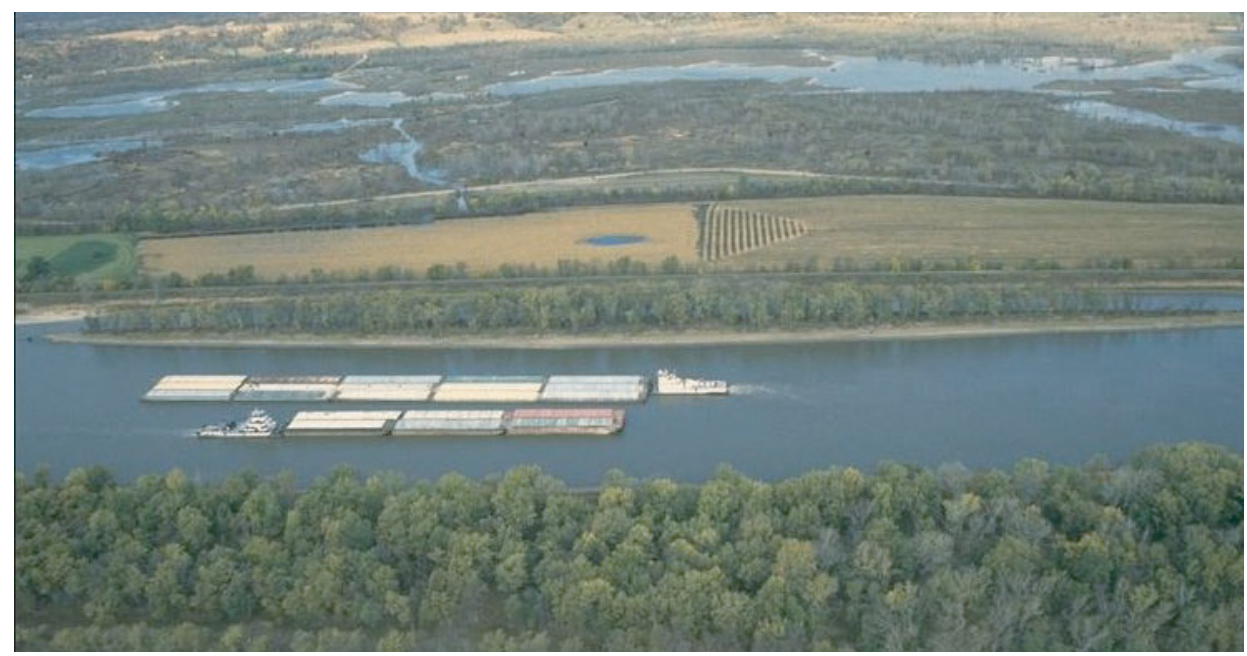

Large rivers provide important shipping channels, but we know little about the effects of commercial shipping on the production of river fishes. We developed the first method for estimation of mortality of adult fish caused by commercial shipping. Our ongoing research seeks to understand whether this mortality and disturbances caused by shipping are significant to the production of river fishes. 